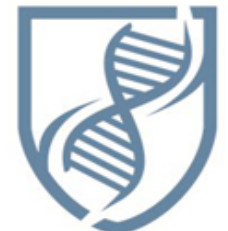

Journal of Bioscience and Applied Research

\section{JBAAR}

WWW.JBAAR.ORG

\title{
Effect of experimental phenylketonuria on some organs of pregnant mothers of albino rats and their young's during perinatal life
}

\author{
Hassan. I. Elsayyad ${ }^{1}$, Hany .A .Hefny ${ }^{2}$ Mahmoud .E. Mohallal ${ }^{3}$ and Hala . M. Ebied $^{3}$ \\ Zoology Department, Faculty of Science, Mansoura University (1) \\ Zoology Department, Faculty of Science ,Suez canal University(2,3) \\ Biology Department, University College, Um Al Qura University Al-jomoum,SA(2) \\ (Corresponding author e.mail. hanyhefny56@hotmail.com)
}

\begin{abstract}
Phenylketonuria (PKU) is a genetic disorder that is characterized by an inability of the body to utilize the essential amino acid, phenylalanine.It results from a deficiency in phenylalanine hydroxylase, the enzyme catalyzing the conversion of phenylalanine to tyrosine. Although this inborn error of metabolism was among the first in humans to be understood biochemically and genetically, little is known about the mechanisms involved in the pathology of PKU during neonatal brain development. Elevated concentrations of plasma phenylalanine were induced in pregnant rats by oral administration of $50 \mathrm{mg} / 100 \mathrm{~g}$ body weight alphamethylphenylalanine (to inhibit maternal liver phenylalanine hydroxylase) plus phenylalanine supplementation) at a dosage of $60 \mathrm{mg} / 100 \mathrm{~g}$ body weight two times daily (to increase maternal and fetal plasma phenylalanine) after 6th day of onset of gestation till 14 \& 16 days of gestation as well as at parturition. Treatment with alpha-methylphenylalanine/phenylalanine resulted in significant decrease of accumulated body weight gain during pregnancy as well as exhibited marked growth retardation of prenatal feti and delivered newborn. Histological examination of maternal tissues including liver, heart, kidney \& thyroid gland revealed varieties of histopathological abnormalities which illustrated and discussed. These results suggested that exposure of the fetus to high plasma concentrations of phenylalanine caused a delay in the biochemical maturation
\end{abstract}

Keywords: Phenylketonuria; pregnanat ,feteus,histological examination.

\section{Introduction}

Phenylketonuria (PKU) disease was first described in 1934 by Asbjorn Falling. Since, he knew that the phenylpyruvic acid was a metabolite of phenylalanine (Phe). Subsequent examinations of PKU patients excreting phenylpyruvic acid proved that phenylalanine was accumulated in their bodies. In phenylketonuria, phenylalanine accumulates in the blood as the result of a normal conditions converts phenylalanine to L-tyrosine (Pietz, 1998)., Individuals with PKU are low in L-tyrosine (Roberts et al., 2001) which may contribute to behavior problems (Tam and Roth, 1997).

Phenylalanine is found in protein foods like milk, meats, eggs, and cheese. However, when the phenylalanine hydroxylase enzyme is absent or deficient, phenylalanine abnormally accumulates in the blood. Inability to remove excess phenylalanine from the blood during infancy and early childhood produces a variety of problems including mental retardation. universal newborn screening can identify the genetic defect and these problems can be greatly reduced by placing the child on a special diet within the first few days of life (Medical Research Council Working Party on PKU 1993).

Moreover, there are two main reasons for a lack of PAH activity. The most common cause is a genetic defect in the gene for $\mathrm{PAH}$, where most patients suffering from PKU have one or another of several possible mutations in this gene. A secondary cause is a defect in the generation of adequate amounts of the cofactor tetrahydrobiopterin (BH4). Tetrahydrobiopterin is an essential coenzyme not only for the hydroxylation of phenylalanine to tyrosine, but also for the hydroxylation of tyrosine to L-doba required for dopamine biosynthesis and for the hydroxylation of 
tryptophan to 5-hydroxytryptophan, the substrate for serotonin biosynthesis. This group appears to constitute 3\% of all hyperphenylalaninemic patients (Kaufman et. al, 1983).

Genetic analysis, using recombinant DNA techniques, has established that the genetic locus for PKU is on chromosome 12. DNA analysis has shown that the classical form of the disease is not due to deletion of the entire gene for $\mathrm{PAH}$, but is instead due to mutations within the gene's sequence leading to amino acid substitutions; results in an enzyme that does not work properly and therefore the body cannot metabolize phenylalanine (Pietz, 1998). The gene for PAH was cloned in 1982 Robson et al. and by now more than 400 different mutations in the PAH gene have been identified, Zschocke (2003) and Scriver et al. (2003).

Maternal PKU is of particular concern. Excessively high or low levels of phenylalanine may occur during pregnancy, both of which may adversely affect the fetus (Brenton and Lilburn, 1996- Maternal PKU can lead to fetal malformations, cardiac abnormalities, intrauterine growth retardation and mental retardation (Levy and Ghavami, 1996; Koch et al., 2000). Adverse effects on the offspring can be reduced by family planning and by careful dietary control both prior to and during pregnancy (Cechaket al., 1996; Riva et al., 1996 and Rouse et al., 1997). In addition, low L-tyrosine levels in pregnant women with PKU may contribute to fetal damage (Rohr et al., 1998). Untreated children with persistent severe hyperphenylalaninemia (Elevated plasma Phe concentration; HPA) show impaired brain development. Signs and symptoms include microcephaly, epilepsy, severe mental retardation, and behavior problems. The excretion of excessive phenylalanine and its metabolites can create a mousy body odor, sensitivity to sunlight and skin conditions such as eczema. The associated inhibition of tyrosinase is responsible for decreased skin and hair pigmentation, light skin. Affected individuals also have decreased myelin formation and dopamine, norepinephrine, and serotonin production. Further problems can emerge later in life and include exaggerated deep tendon reflexes and paraplegia or hemiplegia (Pietzet al. 1998, Williams 1998). The present work aims to illustrate the adverse effect of Phenylketonuria on some organs of pregnant rats; after developmental stages 14th and 16th day of gestation and on delivered newborn.

\section{Materials and Methods}

\section{Experimental animals:}

Eighty fertile virgin female and fertile males of albino rats with an average body weight of $100-110$ grams (ratio of 1 male : 3 females) were obtained from Hellwan Animal Breeding Farm, Ministry of Health, Cairo, Egypt and used for experimentation. Rats were housed in cages in the animal House of Department of Zoology, Faculty of Science, Suez Canal University at ratio of four / cage. They were maintained in a temperature of $20-25 \mathrm{C}$ with $12 \mathrm{~h}$ light- $12 \mathrm{~h}$ dark cycle and stayed for acclimatization for one week before starting the experiments. They were fed on standard diet composed of $50 \%$ grinding barley, $10 \%$ grinding yellow Maize, 20\% milk and 10\% vegetables was supplied. Barley is a very useful grain source for growing, gestating, and lactating dairy cattle, providing more protein than the most other grains as well as showed a highly digestible starch and useful fiber. Barley is an economical nutrient source that should be strongly considered in formulating ratios for dairy animals (Christen et al., 1996). Water and food were available for consumption ad libitum throughout the experimental period. Rats were observed daily and only healthy animals were used in these experiments.

\section{Experimental work:}

Mating was carried out by housing females' rat with fertile males in separate cages at a ratio of three females with one male for overnight between 8 hour pm. till 8 hour am. The presence of vaginal blugs or the presence of sperms in the vaginal smear determined the zero date of gestation.The pregnant mothers was divided into two main groups, thirty animals per each:

I- Control: Thirty pregnant mothers were divided into three subgroups ten animals in each; sacrificed at $14^{\text {th }}$ and $16^{\text {th }}$ day of gestation as well as at parturition.

II- Experimental Phenylketonuria group: Each selected pregnant females at the $6^{\text {th }}$ day of gestation was intragastrically administered 30 mg. DL- $\alpha-$ methylphenylalanine/100 g. body weight (to inhibit maternal phenylalanine hydroxylase) plus $60 \mathrm{mg} / \mathrm{g}$ body weight L-phenylalanine (to raise fetal plasma phenyalanine) dissolved in milk, at $12 \mathrm{~h}$ intervals. The applied dose was selected according to Spero and $\mathrm{Yu}$ (1983) and Rechet al., (2002). The thirty pregnant mothers diseased with experimental PKU were divided into three subgroups ten animals in each; sacrificed at $14^{\text {th }}$ and $16^{\text {th }}$ day of gestation as well as at parturition.

\section{Investigated parameters:}

1- Percentage of mean body weight gain during pregnancy: All of the control and experimental females' rat were weighted at during pregnancy till parturition. The percentage of body weight gain was calculated at $8^{\text {th }}, 10^{\text {th }}$, $12^{\text {th }}, 14^{\text {th }}, 16^{\text {th }}, 18^{\text {th }}$ and $20^{\text {th }}$ days of gestation as follows:

(Mean final body weight - Mean initial body weight) / Mean initial body weight X 100

2- Light microscopic observations: of maternal, fetuses at 14 and 16 days and newborn tissue:

A-At parturition, ten mothers of both control and experimental PKU were sacrificed and rapidly dissected. Maternal liver, heart, kidney, thyroid were removed and immediately fixed in formol saline for 24 hours.

B- Liver, heart and kidney of fetuses at 14 and 16 days and newborn of both control and experimental PKU carried out immediately fixed in $10 \%$ formol saline for 24 hours. The previously mentioned specimens (A and B) were then washed several times in tap water, dehydrated in ascending grades of ethyl alcohol, cleared in terpineol for two days, then washed in benzene for 10 minutes and embedded in three changes of molten paraplast 58-62 C. Serial $6 \mu$ thick histological sections were cut and stained in haematoxylin 
and eosine (Harris HX), Drury and Wallington, 1980), examined carefully under bright field light microscopy and photographed.

3- Statistical analysis: Statistics were calculated with SPSS for windows version 13.0, the means value obtained in the different groups were compared by paired student's t-test. All results were expressed as mean values \pm SE and significance was defined as $\mathrm{p}<0.05$ and highly significant when $<0.01$ (Field, 2000).

4- Transmission electron microscopic (TEM) of maternal liver and heart: Maternal liver and heart of both control and experimental PKU groups were separated and immediately fixed in $2.5 \%$ glutaraldhyde and $2 \%$ paraformoldhyde in $0.1 \mathrm{M}$ cacodylate buffer ( $\mathrm{pH}$ 7.4). After rinsing in $0.1 \mathrm{M}$ cacodylate buffer, samples were post fixed in a buffered solution of $1 \%$ osmium tetraoxide at $4{ }^{\circ} \mathrm{C}$ for 1.5 hour, followed by dehydration in ascending grades of ethyl alcohol and embedded in epoxy-resin. Ultrathin sections were cut with a diamond knife on a LKB microtome and mounted on formvar-coated grids, stained with Uranyl acetate and Lead citrate and examined at Joel Transmission electron microscope

\section{Results}

\section{Effect of PKU on body weight gain}

Body weight gain was recorded in corresponding of starting pregnancy at 7 days for both control and PKU pregnant animals. The percentage of increased body weight reached the highest level at $20^{\text {th }}$ day of gestation. On the other hand, PKU diseased pregnant rats showed much more retardation of growth weight during pregnancy. There was a marked loss of body weight with the advancement of gestation reached the highest reduction of body weight at $20^{\text {th }}$ day of gestation. The percentage of depleted body weight increased steady with the advancement of gestation being $11.89 \%$ at $20^{\text {th }}$ day of gestation (Tab. 1).

\section{Histological observations of maternal tissues}

\section{Liver}

Light microscopic observations revealed that the control liver displayed the histological features of normal structure. (Plate 1fig A and B). Experimental induced PKU mothers exhibited histological abnormalities characterized by erosion of endothelial cells lining the blood vessels associated with sprout dense accumulation of inflammatory cells. There were a marked increase of dissolution of the hepatic cords with prominent dilated blood sinusoids and ill defined cell boundaries of hepatocytes. Numerous zones of densely collected inflammatory cells of varying sizes semi like cellular granulomatous lesions were distributed throughout the hepatic tissues causing obliteration and distortion of hepatocytes. The hepatocytes showed either vacuolar or pyknotic cell degeneration. The blood sinusoids dilated with marked disruption of hepatic cord cell boundaries. Küpffer cells appeared markedly hypertrophied (Plate 1 figs $\mathrm{C}$ and $\mathrm{D}$ ).

\section{Heart}

At the Light microscopic level, the myocardium of maternal ventricle was composed of regularly arranged myocardial fibers. The muscle fiber was separated in to segments at short intervals by intercalated discs. Each cell has a centrally located nucleus (Plate 2 fig A).In experimentally induced PKU mothers, the myocardium possessed variable histopathological abnormalities. Irregular arrangement and fragility of myocardial fibers were detected. The myocardial fibers become widened and infiltrated with focal inflammatory cells. The myocardial fibers appeared eosinophilic with sign of nuclear disintegration and many of their nuclei were immersed in widened zones of inflammatory cells. Partial hyaline necrosis was detected in the majorities of the myocardial fibers (Plate 2 figs B and C).

\section{Kidney}

Histological examination of the control kidney revealed that the control displayed the histological features of normal structure distinguished into an outer cortex and an inner medulla. In the cortex, numerous renal corpuscles were arranged in parallel rows at right angle to the capsule. Bowman's capsule separated by a capsular space Most of the renal parenchyma surrounded the renal corpuscle composed of distal and convoluted tubules (Plate 3 figs. A and $\mathrm{B})$.

In renal tissue of experimentally induced PKU mothers, there was a massive breakdown of renal compartment. The inflammatory cells densely accumulated in between the renal tubules forming cellular granulomatous lesions causing obliteration and degeneration of many of the tubules. The glomeruli showed marked increase of cellularity and swollen leading to occupy all of the Bowman's capsule space. Haline casts were markedly dispersed in both lumen of the tubules as well as in remnants of glomeruli. Some glomeruli exhibited the presence of multinucleated giant cells. The inflammatory cells were also seen dispersed in both peri-glomerular and peri-tubular regions Many of the tubules appeared distorted with massive degeneration of their lining epithelial cells associated with either reduction or missing of their tubular lumina. The epithelia of the visceral and parietal layer of some Bowman's capsule are degenerated with disappearance of the Bowman's space.(Plate 4 Figs. C-D-E $\& F)$.

\section{Thyroid gland}

Histologically, the control shows numerous irregular spheroid follicles contain a homogenous colloid material within their lumen. Each follicle is composed of a single layer of cuboidal epithelial cells bounded by a basement membrane . A thin interfollicular connective tissue layer separated the follicles forming a type of pseudolobulation. (Plate 5 Fig A-B). In induced PKU mothers, many of the thyroid follicles attained a considerable atrophy associated with massive loss many of them. The epithelial lining cells exhibited marked hyperplasia with increased cellular condensation at the periphery. Other follicles exhibited drastic loss of many of their epithelial lining cells. The interfollicular tissue exhibited dense round cell infiltration. The colloid material was markedly reduced or missing in many of the majority of follicles. The stroma become edematous and infiltrated with both numerous hemorrhagic 
spots and inflammatory lymphocytic infiltration. (Plate 5 Figs C-D).

\section{Histological observations of fetal tissues \\ Liver}

The liver of control ,one day postnatal fetus rat shows large number of hepatic lobules and the interlobular connective tissue is poorly developed. the hepatic lobule is formed of hepatocytes and blood sinusoids. The liver of the fetus rat appears to act as a haemopoietic organ. Numerous erythroblasts of advanced maturation stages ; giant cells slightly basiophilic cytoplasm; with no visible nucleoli , are found inside the hepatic sinusoids and in between the hepatic cords. (Figs E and F). The liver tissue of maternally treated feti showed advanced degree of hydropic degeneration, as denoted by the clear cytoplasmic vacuolations and pale cells. There were also less cellularity and diminution of haemopoiesis. The central and portal veins were distended and engorged with stagnant blood (Fig $\mathrm{G}$ and $\mathrm{H}$ ).

\section{Heart}

In control delivered newborn rat, the myocardial muscle shows longitudinally oriented muscle bundles consisting of cardiac myocytes. The nuclei were oval and centrally located within the cell. The cytoplasm showed a normal regularly spaced across striation (Figs. D).In newborn of experimentally induced PKU mother, the myocardium showed areas had a wavy, disorderly appearance and were often not in parallel orientation. The muscle bundles were widely separated from each other. In these areas, sarcomere cross striations were markedly diminished, and the nuclei were often pyknotic with perinuclear vacuolization. Dense round cell infiltration was clearly dispersed throughout the myocardium leading to losing their normal integrity . (Plate 2 figs $\mathrm{E}$ and F).

\section{Kidney}

In control delivered newborn rat, the kidney is differentiated into outer cortex and inner medulla clos $\mathbf{F}$. covered with connective tissue. The kidney cortex contains a large number of Malpighian corpuscles, proximal and distal convoluted tubules. While the medulla is occupied by the ascending and descending loops of Henle. The Malpighian corpuscle is formed of the Bowman's capsule and the glomerulus.. The glomerulus is a tuft of blood capillaries, the walls of which are formed of endothelial cells (Plate- 5 Fig A).

In newborn of experimentally induced PKU mother, kidney showesdegeration of some glomeruli, vacuolar degeneration in some kidney tubules, abnormalities in most of the nuclei lining the tubules in the form of pyknosis, karyorrhexis or karyolysis, focal necrosis of some of the epithelial cells Iinning the kidney tubules. In addition to, intertubu1ar focal lymphocytic infiltration (Plate- 5 Figs B, C).

\section{Transmission electron Micrcoscopy (T EM):}

Transmission electron microscope of maternal liver revealed that the hepatocytes of maternal control possessed centrally located nuclei with prominent electron dense nucleoli. The nuclei showed fine arrangement of heterochromatin at the peripheral zone and main bulk of the nuclei formed mainly of dispersed chromatin. The cytoplasm possessed normal arrangement of mitochondria with prominent cristae distribution. The rough endoplasmic reticulum was densely arranged in parallel strands. Glycogen granules appeared densely dispersed throughout cytoplasm (Plate 6 ,Figs A and B).

\section{Iiver of experimentally induced maternal PKU}

the hepatocytes revealed abnormal cytological alterations. The nucleus appeared shrinking with condensation of chromatin manifesting sign of pyknosis. The granular endoplasmic reticulum appeared fragmented and vesiculated. Numerous fat globules of varying sizes were distributed throughout the cytoplasm. Many of the mitochondria appeared electron dense with missing differentiated cristae. In between the hepatocytes, many of the hypertrophied Kuepfer cells appeared with peculiar chromatin condensation and aligned nearer to newly formed collagen bundle manifesting early sign of fibrosis (Plate 6 ,Figs. C and D).

\section{TEM observations of control maternal heart}

Revealed that the myofibrils appeared densely packed and arranged parallel. Myofibrils showed alternating filament dark (A-band) and light (I-band). The light portion is bisected by a thin dense area, the Z-line, whereas the center of the dark portion is occupied by a less dense zone, the $\mathrm{H}$ band. The part between the two Z-lines is called sarcomere. The intercalated discs are traversed structures found at regular distances at the level of the $\mathrm{Z}$ lines. The nucleus took a spindle shaped structure with peripheral arrangement of heterochromatin and more abundant euchromatin and centrally located in the cardiac cell. The nucleus appeared elongated and centrally located in the cell. The mitochondria distributed abundantly in rows between myofibrilis as well as in subsarcolemmal aggregations. The mitochondria were disposed in longitudinal rows between the myofibrils(Plate 6 ,Figs. E and F).

\section{TEM examination of PKU mothers' heart}

Revealed apparent myodegeneration of the myofibrils which become fragile and loosely separated from each other. Necrotic patches were clearly identified. The mitochondria become swollen and lacked differentiation of their internal component. Many of the mitochondrial were ruptured and degenerated. Plate 6 (Figs. G and H).

\section{Discussion}

Phenylketonuria (PKU) is an inherited metabolic disease, carried through a "recessive" gene. Phenylalanine hydroxylase deficiency is caused by mutations in the $\mathrm{PAH}$ gene resulting in a primary deficiency of the liver enzyme phenylalanine hydroxylase (PAH), (Jervis et al., 1940; Jervis, 1953; Scriver and Kaufman, 2001), and consequently interrupt the conversion of amino acid phenylalanine to another amino acid, tyrosine that results in excessive accumulation of the amino acid phenylalanine and reduced levels of the amino acid L-tyrosine in the blood (Diamond, 1996). Thus phenylalanine accumulates in the blood to concentration sufficiently high to activate an 
alternatively pathway of degeneration (Wurtman and Wurtman, 1979; Gazit et al., 2003).

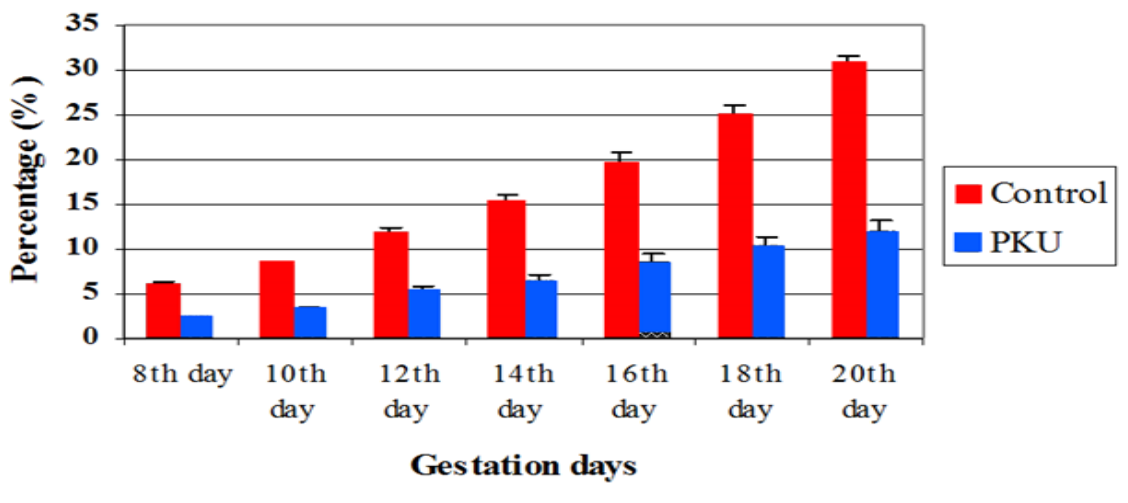

Fig -1: Body weight of fetuses of 14, 16 days prenatal and 1 day postnatal of control and PKUmothers

Table (1): Percentage of increase of body weight gain of control and PKU mothers during pregnancy

\begin{tabular}{|c|c|c|c|c|c|c|c|c|c|c|c|c|c|c|}
\hline & \multicolumn{2}{|c|}{$\begin{array}{l}8^{\text {th }} \text { day of } \\
\text { gestation }\end{array}$} & \multicolumn{2}{|c|}{$\begin{array}{l}\text { 10th day of } \\
\text { gestation }\end{array}$} & \multicolumn{2}{|c|}{$\begin{array}{l}12^{\text {th }} \text { day of } \\
\text { gestation }\end{array}$} & \multicolumn{2}{|c|}{$\begin{array}{l}\text { 14th day of } \\
\text { gestation }\end{array}$} & \multicolumn{2}{|c|}{$\begin{array}{l}\text { 16th day of } \\
\text { gestation }\end{array}$} & \multicolumn{2}{|c|}{$\begin{array}{l}\text { 18th day of } \\
\text { gestation }\end{array}$} & \multicolumn{2}{|c|}{$\begin{array}{l}\text { 20th day of } \\
\text { gestation }\end{array}$} \\
\hline & $\mathrm{C}$ & $\begin{array}{c}\text { PK } \\
\mathbf{U}\end{array}$ & $\mathrm{C}$ & $\begin{array}{c}\text { PK } \\
\mathbf{U}\end{array}$ & $\mathrm{C}$ & $\begin{array}{c}\text { PK } \\
\mathbf{U}\end{array}$ & $\mathrm{C}$ & $\begin{array}{c}\mathbf{P K} \\
\mathbf{U}\end{array}$ & $\mathrm{C}$ & $\begin{array}{c}\text { PK } \\
\mathbf{U}\end{array}$ & $\mathrm{C}$ & $\begin{array}{c}\text { PK } \\
\mathbf{U}\end{array}$ & $\mathrm{C}$ & $\begin{array}{c}\text { PK } \\
\mathbf{U}\end{array}$ \\
\hline Mean & 5.95 & 2.26 & 8.05 & 3.24 & $\begin{array}{c}11.7 \\
2\end{array}$ & 5.34 & $\begin{array}{c}15.1 \\
4\end{array}$ & 6.38 & $\begin{array}{c}19.5 \\
8\end{array}$ & 8.47 & $\begin{array}{c}25.0 \\
1\end{array}$ & $\begin{array}{l}10 . \\
35\end{array}$ & $\begin{array}{c}30.7 \\
7\end{array}$ & $\begin{array}{l}11 . \\
89\end{array}$ \\
\hline \pm S. D. & 0.99 & 0.39 & 0.98 & 0.63 & 1.54 & 1.33 & 2.14 & 1.77 & 2.97 & 2.79 & 2.65 & $\begin{array}{c}2.7 \\
9\end{array}$ & 2.16 & $\begin{array}{c}3.0 \\
4\end{array}$ \\
\hline \pm S. E. & 0.37 & 0.15 & 0.37 & 0.24 & 0.58 & 0.50 & 0.80 & 0.67 & 1.12 & 1.05 & 1.00 & $\begin{array}{c}1.0 \\
5\end{array}$ & 0.82 & $\begin{array}{c}1.1 \\
5\end{array}$ \\
\hline T. Test & & 9.79 & & $\begin{array}{c}11.8 \\
1\end{array}$ & & 6.47 & & 6.89 & & 6.39 & & $\begin{array}{c}8.0 \\
9\end{array}$ & & $\begin{array}{l}11 . \\
59\end{array}$ \\
\hline P. Value & & .000 & & .000 & & .001 & & .000 & & .001 & & $\begin{array}{c}.00 \\
0\end{array}$ & & $\begin{array}{c}.00 \\
0\end{array}$ \\
\hline Significance & & S & & S & & $\mathbf{S}$ & & $\mathbf{S}$ & & S & & S & & $\mathbf{S}$ \\
\hline
\end{tabular}

S. $\mathrm{D}=$ Standard deviation. S. E. = Standard error. $\mathrm{P}=$

Probability. S = Highly significant, $(\mathrm{p}<0.01)$.

In the study of experimentally induced PKU mothers, Our results and those of others confirm this hypothesis. prenatal feta aging 14 and 16 days as well as delivered Jervis (1939) stated that the damage to the children of PKU newborn the myocardium possessed variable mothers is not a genetic consequence (although the children histopathological abnormalities in liver., heart, kidney will be at least heterozygous, as PKU is an autosomal and thyroid gland. Levy and Ghavami, (1996); Koch et al., recessive disorder). This can be proven by the fact that (2000), stated that maternal PKU can lead to fetal PKU fathers produce normal offspring (Fisch et. al. 1991) malformations, including small head size (microcephaly), and also that well controlled pregnant PKU mothers can cardiac abnormalities, intrauterine growth retardation and produce children without obvious handicap.These mental retardation. Exposure to the mother's metabolic symptoms result from high (Phe ) concentrations in the abnormalities affects the fetus during the entire pregnancy. blood of the fetus. It is a consequence of intrauterine(Phe) The abnormalities produced by the PKU mothers are not excess resulting from the positive transplacental ( Phe) genetic but "Intrauterine Environmental" . gradient. To keep fetal blood (Phe) below $500 \mu \mathrm{mol} / \mathrm{l}$ maternal concentration should be below $300 \mu \mathrm{mol} / \mathrm{l}$ (Gardiner, 1990 and Schoonheyt, et al. 1994). 


\section{Plate -1: Photomicrograph of histological section of rat liver.}

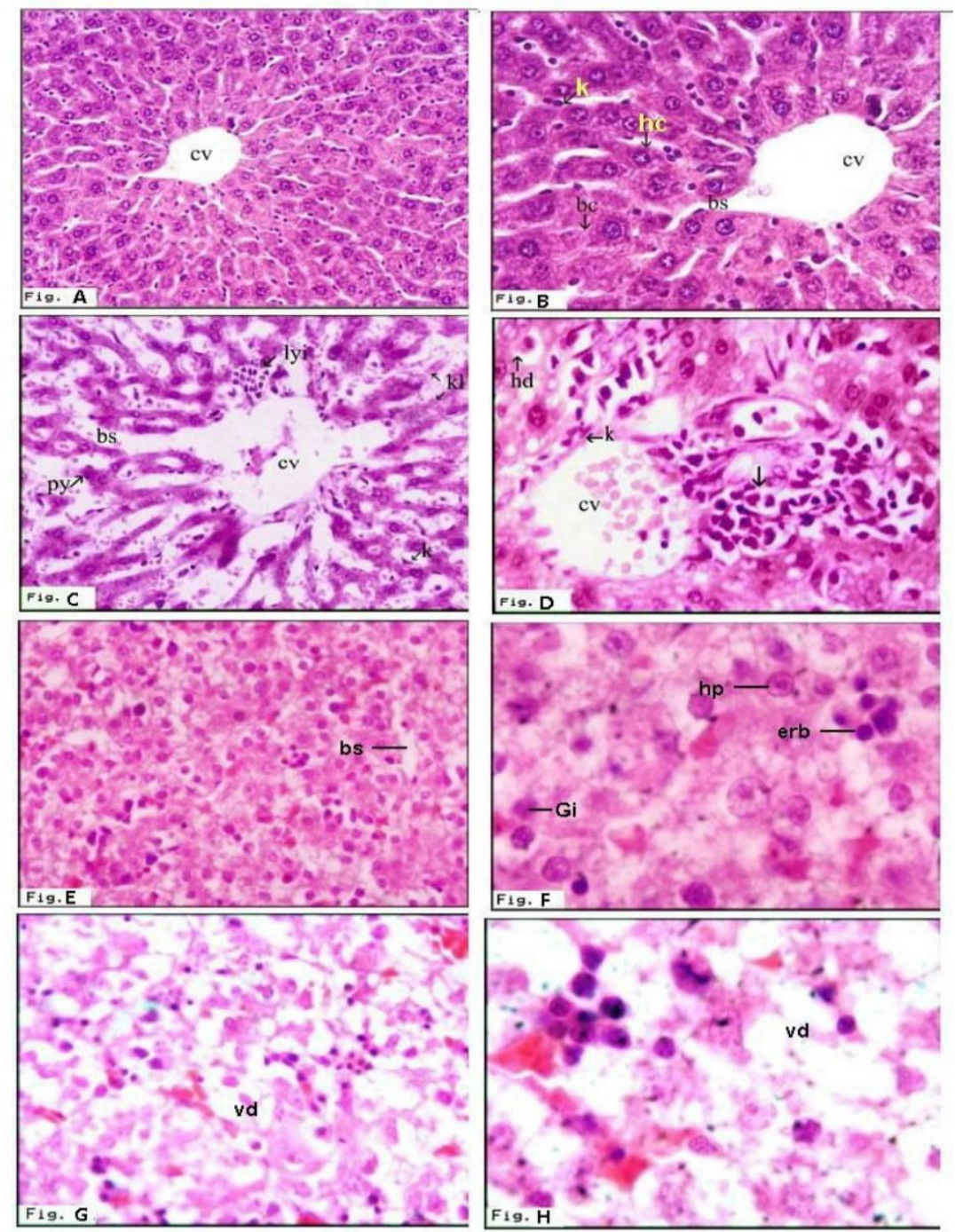

Aand B : control maternal liver showing normal hepatic lobule with normal hepatocytes (hp) around a central vein (cv). The blood sinusoids (bs) are limited by the flattened endothelial cells the Küpffer cells (k) . A X( 200) - B X ( 400) C and D: maternal induced PKU liver. C-Showing abnormal architecture of hepatic lobule with peculiar dissolution of hepatic cord with dilatation of blood sinusoids, degeneration of endothelial cells lining the blood vessel, focal lymphocytic infiltration (arrow) around central vein (cv) and massive increase of pyknotic hepatocytes (py) . DShowing eroded epithelial cells lining the blood vessels, dilated sinusoids (bs), sprouts of inflammatory cells (lyi), karyolysis (kl) and pyknosis of nuclei and hypertrophy and of Küpffer cell (k).(A X 400- B X 400)E and F: offspring of control liver, showing normal hepatocytes (hp) alternate with blood sinusoids (bs) and Giant cells( Gi). Notice that the hepatic cords and sinusoids containing erythroblasts (erb). (AX 400 - BX 1000)G and H: offspring of experimentally induced PKU mother showing, hepatocytic vacuolar degeneration (vd) . (GX 400 - HX 1000) 


\section{Plate -2: Photomicrograph of histological section of myocardium of rat}
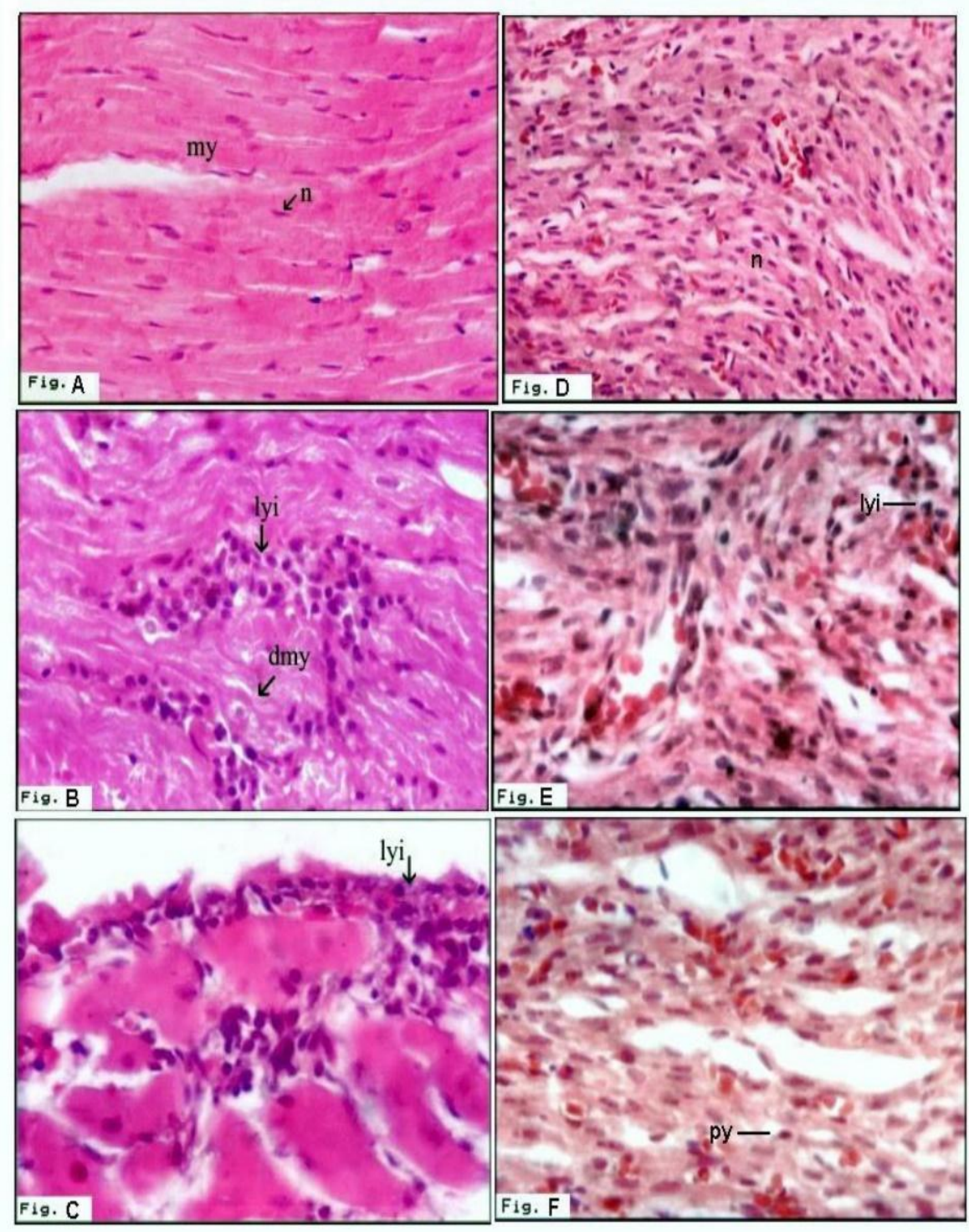

A-control mother showing regularly arranged myocardial fibers (my) with prominent centrally located nuclei (n). (AX 400).B-C): PKU mother B- showing fragility of myocardial fibers, degenerated myofibrils (dmy) and focal lymphocytic infiltration (lyi). C- showing necrotic zones of myocardial fibers with dense collection of inflammatory cells (lyi). B X 400- CX 400).

D: offspring control showing normal pattern of relatively straight, cylindrical and parrallel myocytes. The nuclei (n) were oval and centrally located within the cell. The cytoplasm showed a normal pattern of regularly spaced across striation. (D X 250). E and F: offspring of experimentally induced PKU mother showing a wavy and disorderly oriented myocytes. The muscle bundles were widley separated from each other with markedly diminished cross striations and the nuclei were often pyknotic (py) with perinuclear vacuolization. 


\section{Plate -3: Photomicrograph of histological section of the maternal kidney}
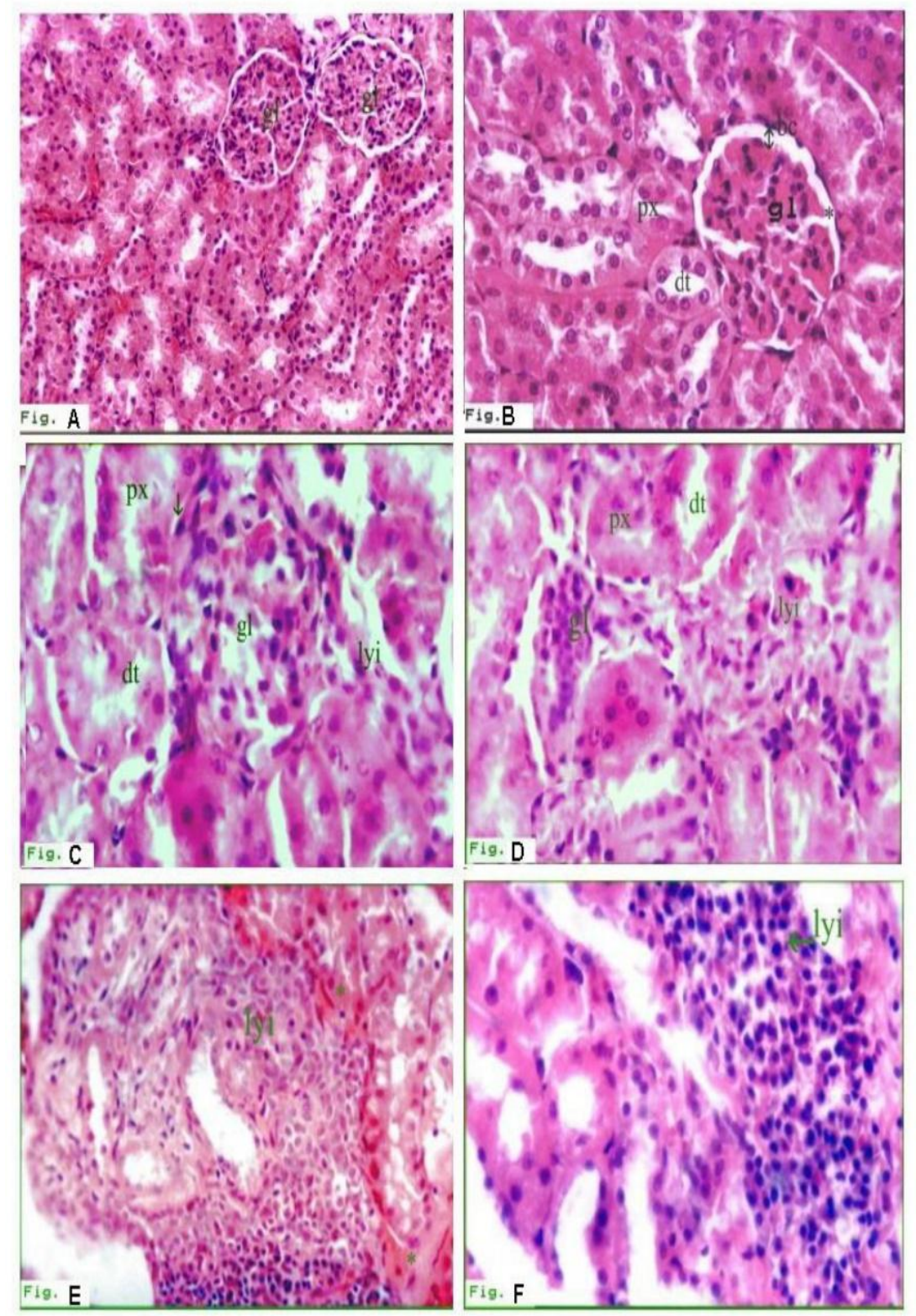

A and B: Control maternal kidney showing a part of the cortical region containing a renal corpuscle that consists of Bowman's capsule enclosing the glomerulus (gl). The Bowman's capsule (bc) is formed of the parietal and visceral layers separated by the urinary space (*). Also portions of proximal (px) and distal (dt) convoluted tubules are illustrated (A X 250 - B X 400).

\section{Photomicrograph of histological section of the kidney of PKU mother}

C - Showing -distended glomeruli (gl) with marked increase of cellularity and infiltrated by hyaline casts as well as missing of Bowman's space (arrow). The epithelial cells lining both the proximal (pt) and distal (dt) convoluted tubules appeared deteriorated. Fine collection of peritubular inflammatory cell infiltration (lyi) is detected. D -Showing degenerated glomeruli (gl) with accumulated Hyaline casts.

The renal tubules appear distorted with detected degeneration of their epithelial lining cells. Focal inter tubular inflammatory cell infiltration (lyi) is detected. ( C X 400- D X 400).E and F: showing dense inflammatory cell infiltration (lyi) forming granulomatous lesions causing obliteration and degeneration of renal tubules. Notice, an area of internal hemorrhage $(*)$ infiltrated the renal tubules. (E X 250 - F X 400). 


\section{Plate -4: Photomicrograph of histological section of the kidney of offspring}

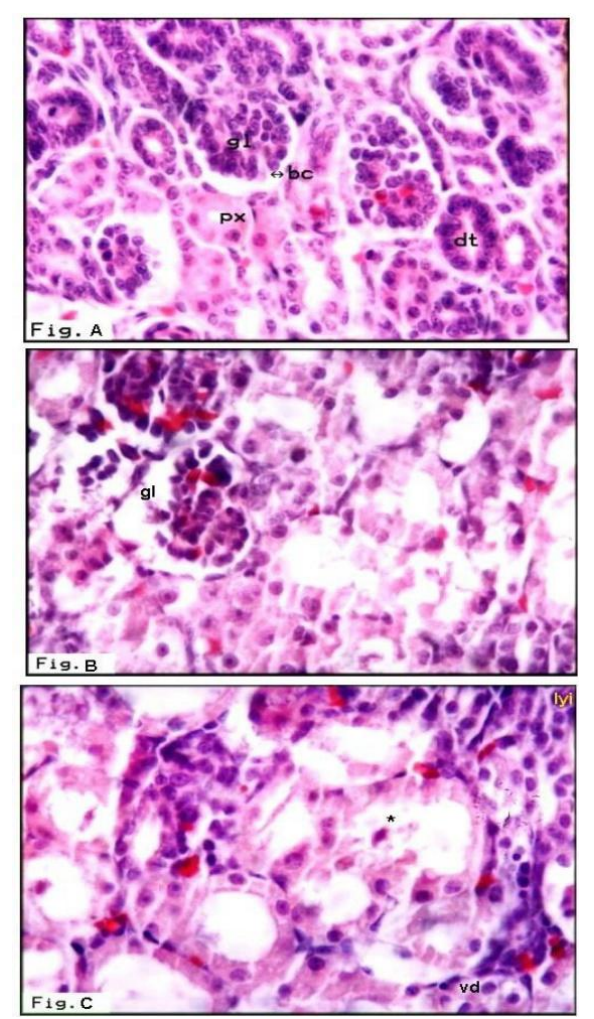

A: Offspring of control rat showing normal structure of Bowman's capsule (be), glomerulus (gl), portions of proximal (px) and distal ( dt) convoluted tubules are illustrated . (X 400).B and C: Offspring of experimentally induced PKU mother showing, degenerated glomerulus (gl), vacuolar degeneration in some kidney tubules (vd),

focal necrosis of the epithelial cells linning the kidney tubules $(*)$. In addition to, inter tubular focal lymphocytic infiltration (lyi).( A X 400- B X 400

\section{Plate -5: Photomicrograph of histological section of maternal Thyroid gland}

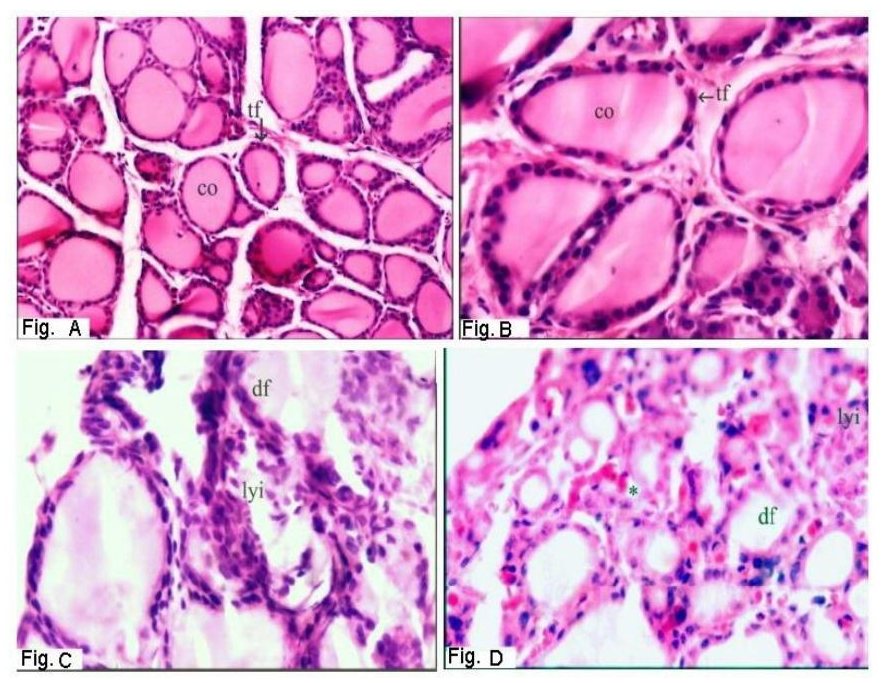

A and B: section of thyroid of control mother showing irregular spheroid thyroid follicles (tf) with colloid material (co) within their lumen. (A X 100 - B X 250).

C and D: section of thyroid of PKU mother. C-Showing massive degenerated follicles (df). D-Showing atrophied follicles (df) with missing colloids associated with lymphocytic infiltration (lyi). Many of the follicular lining cells appear hyalinized. The stroma become edematous stroma infiltrated with numerous hemorrhagic spots $(*)$ and possess lymphocytic infiltration (lyi). 
Plate -6: Transmission Electron microscopic (TEM) photomicrograph of Maternal Liver and Heart

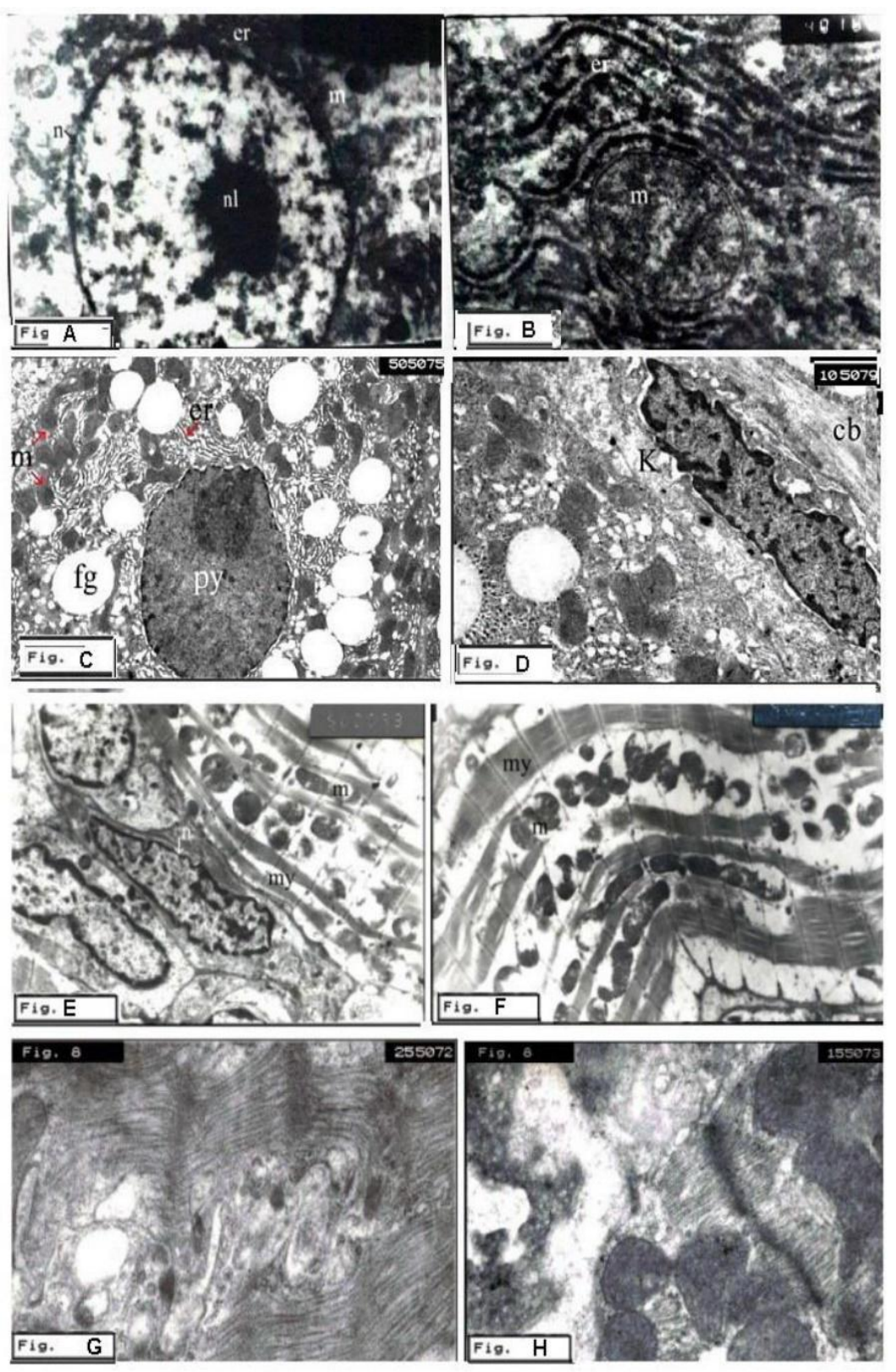

TEM: photomicrograph of maternal Liver of control maternal hepatocyte Plate 7 (A-B): (TEM) showing centrally located nuclei (n) with differentiated nuclear membrane and prominent nucleolus (nl) Mitochondria (m), rough endoplasmic reticulum (er) and glycogen are clearly identified throughout the cytoplasm. (X6700). (C-D): TEM Photomicrograph of hepatic tissue of PKU mother showing nuclei with dense chromatin condensation manifesting pyknosis (py). The cytoplasm encloses by numerous fat globules (fg) of varying sizes, fragmented and vesiculated rough endoplasmic reticulum (er) and atrophied mitochondria (m) with ill differentiated cristae. D-Showing hypertrophied Küpffer cell (k) with peculiar nuclear chromatin condensation nearer to newly formed collagen bundles (cb). ( A X 5000 - B X 10000).

\section{(TEM photomicrograph of maternal heart}

Plate 7: (E and F) control heart mother. E-showing longitudinal parallel rows of myofibrils (my) and gathered in between mitochondria $(\mathrm{m})$ arranged inregular manner. F-Showing elongated cigar-shaped nuclei of myofibrils (n) as well as the intercalated disc at regular distances. (A X 4000- B X 5000). (G and H): heart of PKU mother. G-Showing necrotic myocardialfibrils (my) enclosed in-between swollen mitochondria $(\mathrm{m}) \quad \mathrm{H}$-Showing irregular distribution of myofibrils with disruption of band arrangement.A X 15000 - B X 25000) 
The thyroid hormones are very important during foetal and neonatal growth (GLinoer, 1997).Histological abnormalities in thyroid with reduction of thyroid colloid may declare disruption of thyroid hormone and responsible for growth defect. Disturbance of phenylalanine metabolism interferes 5 References

Brenton, D.P. \& Lilburn, M. (1996). Maternal phenylketonuria. A study from the United Kingdom.Eur J Pediatr ;155Suppl 1:S177-80.

Cechak P, Hejcmanova L, Rupp A.(1996). Longterm follow-up of patients treated for phenylketonuria (PKU). Results from the Prague PKU Center.Eur J Pediatr;155Suppl 1:S59-63

Christen, S. D.; T. M. Hill, M. S. \& Williams, H. (1996). Effectes of tempered barely on milk yeiled, intake and digestion kinetics of lactating holstein cows. J. Dairy. Sci.; 79: 1394-1399.

Diamond A. (1996): Evidence for the importance of dopamine for prefrontal cortex functions early in life. Philos Trans R SocLond B Biol Sci;351:1483-93 .

Drury, R.A. and Wallington, E. A. (1980): Carleton histological technique. 5th edition.Published by Oxford Univ. Press London, New York.Tonto.

Falling A (1934). Uber Aus scheidung von Phenylbrenztraubensaure in den Harnals Stoffwechselanomalie in VerbindungmitImbezillitat. A Physiol Chem, 1934; 227: 169-176

Field, A. P. (2000). Discovering statistics using SPSS for windows: advanced techniques for the beginner. Sage publications, London.

Fisch, R. O., Matalon, R., Weisberg, S. and Michaels, K. (1991). Children of fathers with withphenykketonuria: An international survey. J. Pediatr.(118): 739-741.

Gardiner RM(1990). Transport of amino acids across the blood-brain barrier. Implications for treatment of maternal phenylketonuria. J Inherit. Metab. Dis, 1990, 13: 627.er, 1990

Gazit, V.: Ben-Abraham, R.; Pick ,C.G.(2003). Betaphenyl pyruvate induces long-term neurobehavioral damage and brain necrosis in neonatal mice .Behav. Brain Res.;143(1):1-5

Glinoer ,D (1997). The regulation of thyroid function in pregnancy pathway of endocrine adaptation from physiology to pathology.Endocr.Rev .18:404.

Jervis G. A. (1939). Genetics phenylpyruvicoligophrenia. (Contribution to study of influence of heredity on mental defect). J. Ment. Sci. (85): 719-762

Jervis, G. A. (1940). Block RJ, Bolling D, Kanze E: Chemical and metabolic studies on phenylalanine. The phenylalanine content of the blood and spinal fluid in phenylpyruvicoligophrenia. J Biol Chem; 134: 105-113. with the formation of unusual metabolites causing adverse effect of the development via its effects on dopamine, which reproduce the cytotoxicity manifested in both pregnant mothers of albino rats and its young's

Jervis, G.A. (1953). Phenylpyruvicoligophrenia. Deficiency of phenylalanineoxidizing system. Proc SocExpBiol Med; 82: 514-515

Kaufman S, Kapatos G, Rizzo WB, Schulman JD, Tamarkin L, Van Loon GR. (1983). Tetrahydrobiopterin therapy for hyperphenylalaninemia caused by defective synthesis of tetrahydrobiopterin. Ann Neurol; 308-15

Koch, R.. Hanley, W. and Levy, H. (2000). Maternal Phenylketonuria: An International Study. Molecular Genetics and Metabolism. . 71( 1-2): 233-239.

Levy, H.L. and Ghavami, M. (1996). Maternal phenylketonuria: a metabolic teratogen. Teratology; 53:176-84 .

Medical Research Council Working Party on PKU 1993).Recommendations on the dietary management of Phenylketonuria. Arch. Dis. Child; 68:426.

Pietz, J.(1998): Neurological aspects of adult phenylketonuria. CurrOpinNeurol; 11:679-88

Rech, V.C.; Feksa, L.R., Dutra-Filho; C.S., Wyse, A.T. Wajner, M. \&Wannmacher, C.M. (2002). Inhibition of the mitochondrial respiratory chain by phenylalanine in rat cerebral cortex. Neurochem.Res. 27(5):353-357.

Riva E, Agostoni C, Biasucci G, et al (1996). Early breastfeeding is linked to higher intelligence quotient scores in dietary treated phenylketonuric children. Acta Paediatr; 85:56-8. 1

Roberts, S.A.; Thorpe, J. M.; Ball, R.O. et al. (2001). Tyrosine requirements of healthy men receiving fixed phenylalanine intake determined by using indicator amino acid. Am. J. Clin. Nut.; 73(2): 276-282

Robson KJH, Chandra T, Mac Gillivray RTA, Woo SLC (1982). Polysome immunoprecipitation of phenylalanine hydroxylase mRNA from rat liver and cloning of its cDNA. Proc Natl Acad Sci USA; 79: 47014705

Rohr, F.J., Lobbregt, D. and Levy, H.L. (1998). Tyrosine supplementation in the treatment of maternal phenylketonuria. Am J ClinNutr .67:473-6

Rouse, B., Azen, C., Koch, R., Matalon, R., Hanley, W., de la Cruz, F., Trefz, F., Friedman, E. and Shifrin, H. (1997): Maternal phenylketonuria collaborative study (MPKUCS) offspring: facial anomalies, malformations, and early neurological sequelae. Am. J. Med. Genet. 69: 89-95.

Schoonheyt WE, Clarke JTR, Hanley WB, Johnson LM, Lehotay DC (1994). Feto-maternal plasma phenylalanine concentration gradient from 19 weeks gestation to term. Clin Chim Acta, 225: 165-169 
Scriver CR, Kaufman S (2001). The hyperphenylalaninemias. In: Scriver CR, Beaudet AL, Sly SW, Valle D (eds) Childs B, Kinzler KW, Vogelstein B (assoc eds) The Metabolic and Molecular Bases of Inherited Disease, 8 ed. McGraw-Hill, New York.

Scriver CR, Hurtubise M, Konecki D, Phommarinh M, Prevost L, Erlandsen H, Stevens R, Waters PJ, Ryan S, McDonald D, Sarkissian C (2003) PAHdb 2003: what a locus-specific knowledge base can do. Hum Mutat 21:33344 .

Spero, D.A. \& Yu, M.C. (1983a). Effects of maternal hyperphenylalaninemia on fetal brain development: a morphological study. Exp.Neurol. ;79(3):655-665
Tam, S.Y. , Roth, R.H. (1997). Mesoprefrontal dopaminergic neurons: can tyrosine availability influence their functions?.Biochem Pharmacol;53:441-53

Williams K (1998). Benefits of normalizing plasma phenylalanine: impact on behaviour and health. A case report. J Inherit Metab Dis 21:785-90 .

Wurtman, R.J. ,Wurtman, J.J. (1979). Toxic effects of food constituents on the brain. In G. Guroff (Ed.).Nutrition and the brain Vol. 4. New York: Raven Press, 29-78

Zschocke, J.(2003). Phenylketonuria mutations in Europe. Hum Mutat ;21(4):345-56. 